\title{
DYNAMIC ANALYSIS OF STEEL TUBE STRUCTURE WITH BRACING SYSTEMS
}

\author{
Dhanapalagoud Patil ${ }^{1}$, Naveena $M P^{2}$ \\ ${ }^{1}$ Student, Structural Engineering, MVJ College of Engg, Karnataka, India \\ ${ }^{2}$ Assistant Professor, Structural Engineering, MVJ College of Engg, Karnataka, India
}

\begin{abstract}
Nowadays, competition towards rise of tall steel structures made certain factors are compulsory like serviceability and comfort of human relating to lateral loads caused by wind or earthquake. Earthquake is dangerous to the living beings in terms of its effects on manmade structures. Structures like tall buildings are built to resist gravity loads. However many tall buildings are not so resistant in lateral loads due to earthquake so need an improvement in resisting lateral loads. So there are many structural systems which resist lateral loads by varying orientation, addition of different structural systems. Like steel tubular structural system is considered and compared for their results against lateral forces and also by providing mega bracing system and diagrid bracing system. In this dissertation work, four structural systems are considered in which one is framed structure and rest are tubular system with addition of different bracing systems as mega bracing and diagrid bracing system. For the purpose 45 storey steel structure with rectangular plan of dimension $44 m x 24 m$ uniform throughout the height is considered and analyzed for gravity and lateral loads using ETABS software. Its intention is to obtain the functioning characteristics like displacements, storey shear, time period, frequency, peak displacement and peak acceleration in both $x$ and y direction to get most economical structure in all ways. Results shows that the steel tubular structure with mega bracing system performance is much better than the framed structure, tubular and tubular structure with diagrid bracing system.
\end{abstract}

Keywords: Steel Tube Structure, Mega Bracing, Diagrid Bracing, Dynamic Analysis, ETABS, Time and History Analysis.

\section{INTRODUCTION}

Structures are being used from the antiquated times, where as the change in human's life made tall structures more adoptable for their economic wellbeing, requirement for their most elevated eminence in the general public for their legendry. Now days the development of urban communities by relocation of individuals from their local to lovely urban areas made more thickness more than a territory as a result ascent of tall structures have been happened. However science, technology, architect have also influencing the ascent of tall buildings. In tall structures the tallness is comparative term. Exact definition of tall structures cannot be applied worldwide. From structural engineering point of view tall structures must resist gravity and also lateral loads. The competition towards rise of tall structures have made significant about the design of building to resist against lateral load. The geometry of the building also not the fundamental criteria to design the tall and slender building yet the drift of the building is responsible for stresses developed in the building. Various structural systems are raised for stabilization of tall building against lateral loads like shear frames, belt truss with out-rigged system, frames with bracings, super columns, shear wall, wall-frame, braced tube system, outrigger system, tubular system, mega bracing. Recently, the Diagrid - Diagonal Grid - structural system is widely used.

\subsection{Scope and Objective.}

- An attempt has been made to Analyze the fallowing tall structure using conventional software ETABS. 1) Frame structure, 2) Tube Structure, 3) Tube Structure with mega bracings, 4) Tube Structure with Diagrid bracings.

- Numbers of stories considered are 45 stories, each of height $4 \mathrm{~m}$ for all models.

- To investigate and study by applying different available structural systems. For minimizing the deflection under lateral loading.

- $\quad$ Structures are analyzed using equivalent static analysis and dynamic analysis for particular soil and zone.

- Responses of different structural systems are studied in terms of displacements, story drifts.

- Conclusions are drawn based on the observations and better structural system is found out with this study.

\subsection{Concept of Tubular System}

$\checkmark$ The main ideology of tubular structure is to resist horizontal load by arranging structural element efficiently.

$\checkmark$ In this system many elements contribute to resist loads like slabs columns beams mainly spandrel beams and columns at the periphery of the building resist lateral load. 
The interior core of the building is to resist gravity load.

The distance between the interior and external frame is connected by beams and slab or only slab to resist gravity load.

\subsection{Framed Tube Behavior}

This type of structure has columns spaced closely at the perimeter and columns joined by beams which resist lateral loads. This creates tube as continues perforated chimney. Stiff moment resistant between beam and column provides lateral stiffness. This type of structure is constructed for 40 and 60 stories above up to 100 stories. The columns and beams frame along loading direction of loading acts as web frames and normal to the direction of loading acts as flange frames. Shear lag is suffered by flange frames which results in less stressed at internal tube and more stressed at external corner columns. This type of structure will have large floor openings and internal columns will resist vertical load only.

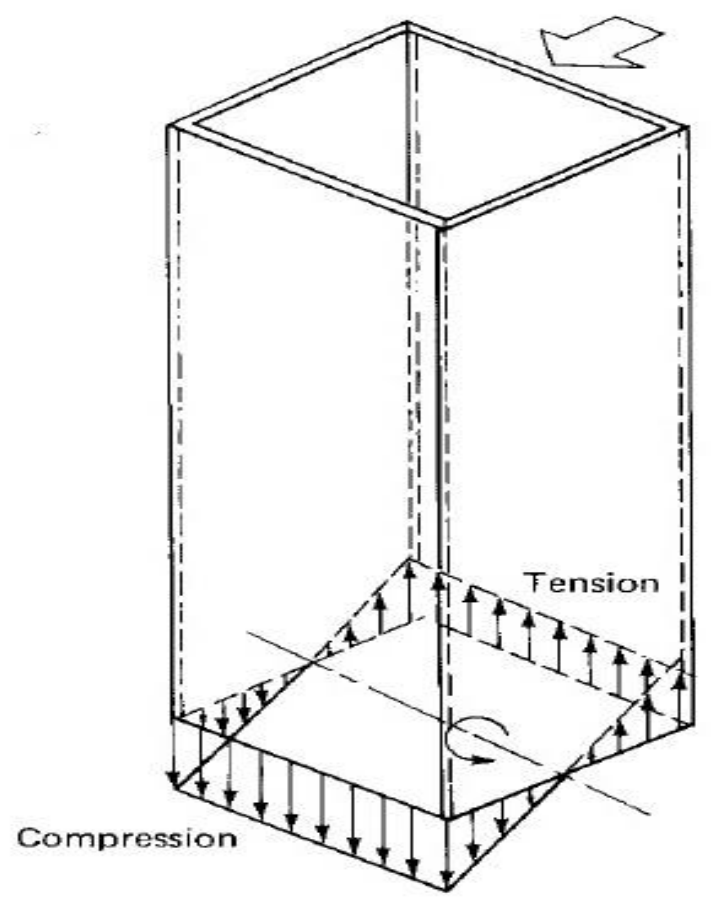

Fig - 1: Framed Tube Structure Behavior

\subsection{Shears Lag in Tube Structure}

The frames normal to the loading are called flange frames and perpendicular to the loading are web frames. The axial force distribution of the web and flange frames is shown in Fig - 2. The ideal tube behavior tells that uniform axial force in flange frame and varying in web frame. In framed tube structure the axial force will be maximum at the corner and reduces at the centre due to high rigidity of a spandrel beam. The axial strength in the inner column will lag behind corner column because of less sharing rigidity among the inner and outer frames. This is known as shear-lag. Negative shear-lag observed as the axial force allocation shown in Fig -2, will be reverse at the top of the building.
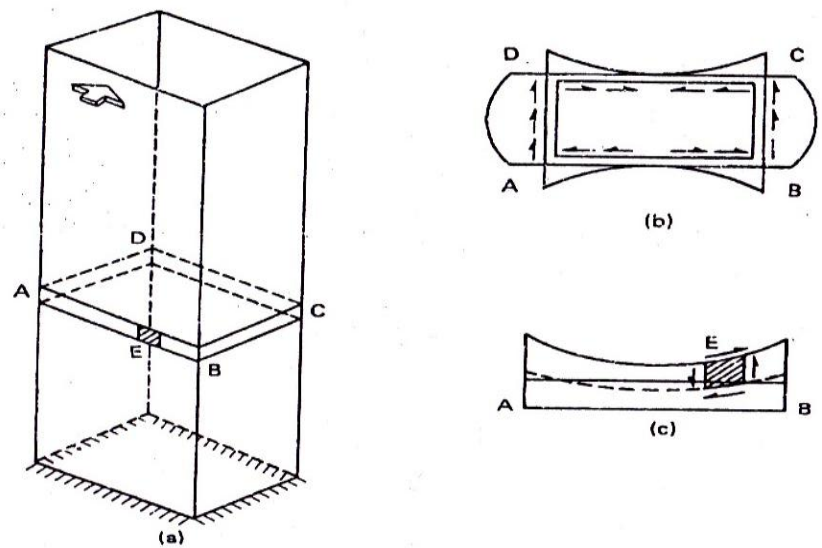

(b)

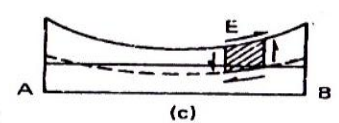

Fig - 2: Shear Lag Effect in Tube Structures.(a)Cantilever tube subjected to lateral loads; (b) Shear stress distribution; (c) distribution of flange element caused by shear stresses.

\subsection{Tube Structure with Mega Bracings}

With the increment in utilizing tall steel braced tube structures, the significance of different propping setups to have the best execution and the most reduced material was more considered. External larger scale bracing, stretching out over numerous stories, has been utilized to deliver exceptionally proficient structures, as well as attractively appealing structures. The diagonal components that keep running over a bay or face of the building fasten the entire structure together and convert the building into a vertical cantilever beam. In the braced tube structures the bracing contributes also enhanced execution of the tube in conveying gravity loading, differences between gravity load stresses in the columns are leveled out by the braces transferring axial loading from the more highly to the less highly stressed columns. In this dissertation work the diagonal bracing is provided for every 5 stories.

\subsection{Tube Structure with Diagrids Bracing System}

Configuration and development of counterfeit foundation on the lines of biomimicking standards requires the improvement of much progressed structural frameworks which has the characteristics of aesthetic expression, basic productivity and in particular geometric flexibility. Diagrids, the most recent transformation of tubular structures, have an ideal blend of the above qualities. The Diagrids are perimeter structural setup characterized by a narrow grid of diagonal members which are implicated both in gravity and in lateral load resistance. Diagonalized applications of structural steel members for providing well organized solutions both in terms of strength and stiffness are not new, however nowadays a renewed interest in and a widespread application of Diagrid is registered with reference to large span and tall structures, predominantly when they are characterized by complex geometries and curved shapes, sometimes by completely free forms.

As in the Diagrids, diagonals convey both shear and moment. Therefore, the ideal point of diagonals is exceptionally needy upon the building height. Since the optimal point of the segments for most extreme bending rigidity is 90 degrees and that of the diagonals for greatest shear rigidity is about 35 degrees, it is expected that the 
optimal angle of diagonal members for Diagrid structures will fall between these angles and as the building height increases, the optimal angle also increases. Usually adopted range is $60^{\circ}-70^{\circ}$ degree. In this case $60^{\circ}$ is provided.

\section{METHODOLOGY}

To achieve the above objective following step-by-step procedures are followed

- Carried out literature study to find out the objectives of the project work.

- Understand the Earthquake loading analysis of Steel Tube Structure with Bracing Systems is carried out as per Indian Standard IS 1893(part 1):2002.

- Analyse all the selected Steel Tube Structure models using ETABS Software.

- Evaluate the analysis results and verify the requirement of the geometrical limitations.

\subsection{Dimensional Description of Steel Tube}

\section{Structure with Bracing Systems.}

In this study four types of models are chosen. The plan, height of floor, no of Stories, deck slab thickness remains the same for all the models. Plan dimension of all models is $44 \mathrm{~m} \times 24 \mathrm{~m}$ and inner core of dimension $12 \mathrm{~m} \times 8 \mathrm{~m}$. The total height of the structure is 180 meter. Each floor height is 4 meter, floor of steel composite deck of thickness 175 $\mathrm{mm}$ and $200 \mathrm{~mm}$, the built up column dimension is ISWB 600 , beam is ISMB - 600, and the live load is taken as $4 \mathrm{kN} / \mathrm{m}^{2}$, SDL of $2 \mathrm{kN} / \mathrm{m}^{2}$ and glazing of $6 \mathrm{kN} / \mathrm{m}^{2}$ are considered. In mega bracing system the bracings ISWB-600 are provided for every 5stories interval and in Diagrid Bracing system the bracings ISWB - 600 are provided at an angle of $60^{\circ}$.

\subsection{Basic Data for Modeling}

- $\quad$ Type of soil = medium soil

- Seismic zone = IV

- Importance factor $=1$

- Response reduction factor $=5$

- Height of Structure $=180 \mathrm{~m}$.

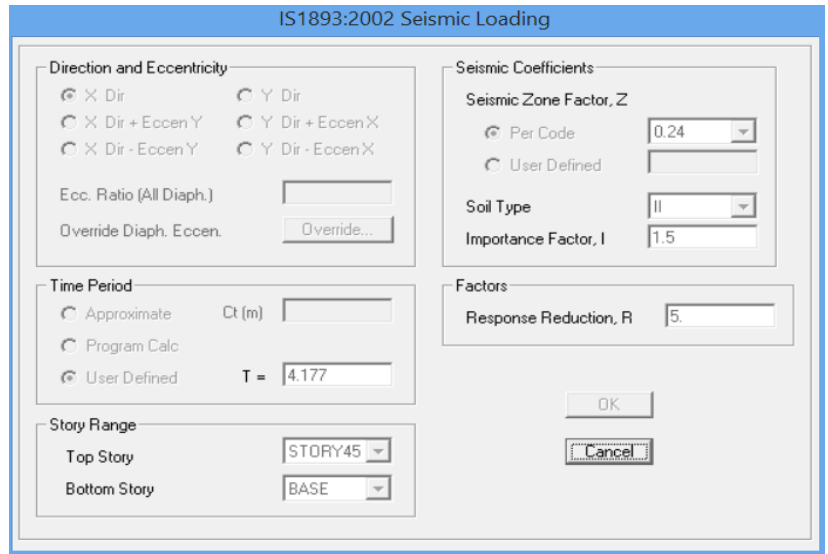

Table - 1: IS 1893:2002 Sesmic Loading.

$$
\mathrm{T}_{\mathrm{a}}=0.085(180)^{0.75}=4.177
$$

\begin{tabular}{|c|c|c|c|c|c|c|c|c|c|}
\hline \multirow[t]{3}{*}{ Combination } & \multicolumn{6}{|c|}{ Limit State of Strength } & \multirow{2}{*}{\multicolumn{2}{|c|}{$\begin{array}{c}\begin{array}{c}\text { Limit State of } \\
\text { Serviceability }\end{array} \\
\text { L. }\end{array}$}} & \multirow[t]{3}{*}{ WL/EL. } \\
\hline & \multirow[t]{2}{*}{ DL. } & \multicolumn{2}{|c|}{ LL. } & \multirow{2}{*}{$\begin{array}{c}\text { WLL/ } \\
\text { EI. }\end{array}$} & \multirow[t]{2}{*}{ AL } & \multirow[t]{2}{*}{ DL. } & & & \\
\hline & & Leading & $\begin{array}{l}\text { Accompanying } \\
\text { (CL, SL etc.) }\end{array}$ & & & & Leading & $\begin{array}{l}\text { Accompanying } \\
\text { (CL, SL etc) }\end{array}$ & \\
\hline $\mathrm{DL}+\mathrm{HL}+\mathrm{CL}$ & 1.5 & 1.5 & 1.05 & $\cdot$ &. & 1.0 & 1.0 & 1.0 &. \\
\hline $\mathrm{DL}+\mathrm{LL}+\mathrm{CL}+$ & 1.2 & 1.2 & 1.05 & 0.6 & . & 1.0 & 0.8 & 0.8 & 0.8 \\
\hline WL/EL & 1.2 & 1.2 & 0.53 & 1.2 & & & & & \\
\hline $\mathrm{DL}+\mathrm{IVL} / \mathrm{EL}$ & $\begin{array}{l}1.5 \\
(0.9)^{*}\end{array}$ & . & . & 1.5 & . & 1.0 & . & . & 1.0 \\
\hline DL.+ER & $\begin{array}{l}1.2 \\
(0.9)\end{array}$ & 1.2 & - & . & . & . & . & . & \\
\hline DL.LL+AL. & $\begin{array}{l}1.0 \\
0.35\end{array}$ & 0.35 & . & 1.0 & . & . & . & & \\
\hline
\end{tabular}

Table - 2: Load Combination for Analysis.

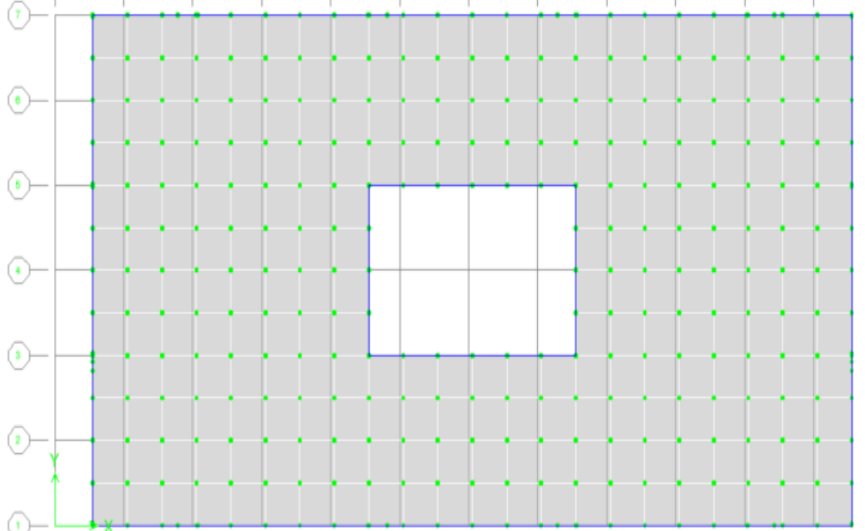

Fig - 3: Plan for All Model Analysis

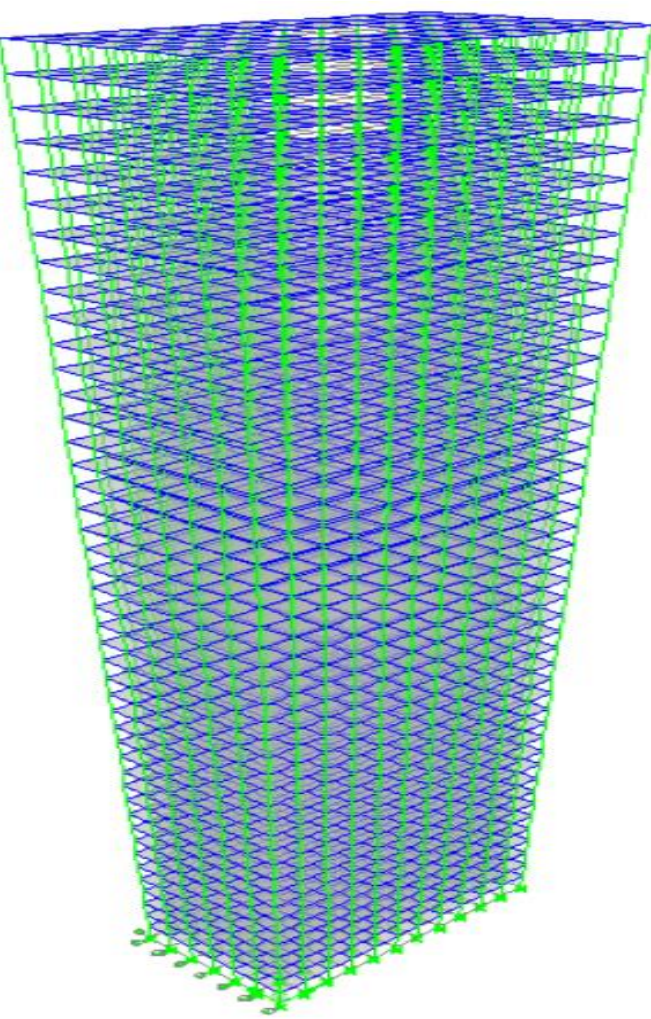

Fig - 4: Steel Frame Structure Model M1. 


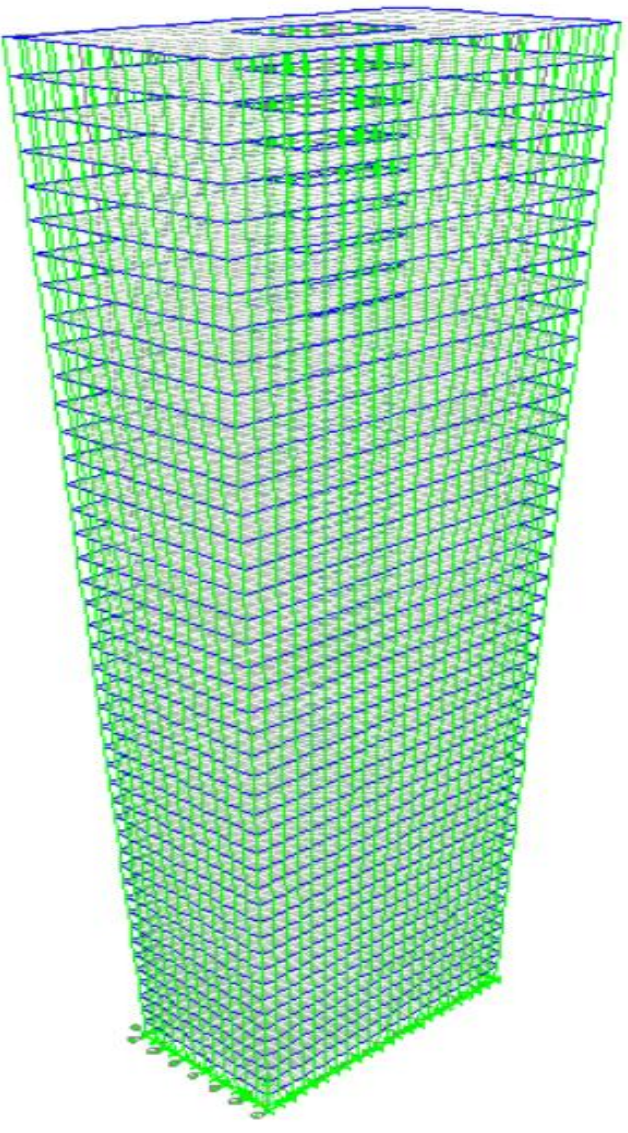

Fig - 5: Steel Tubular Structure Model M2

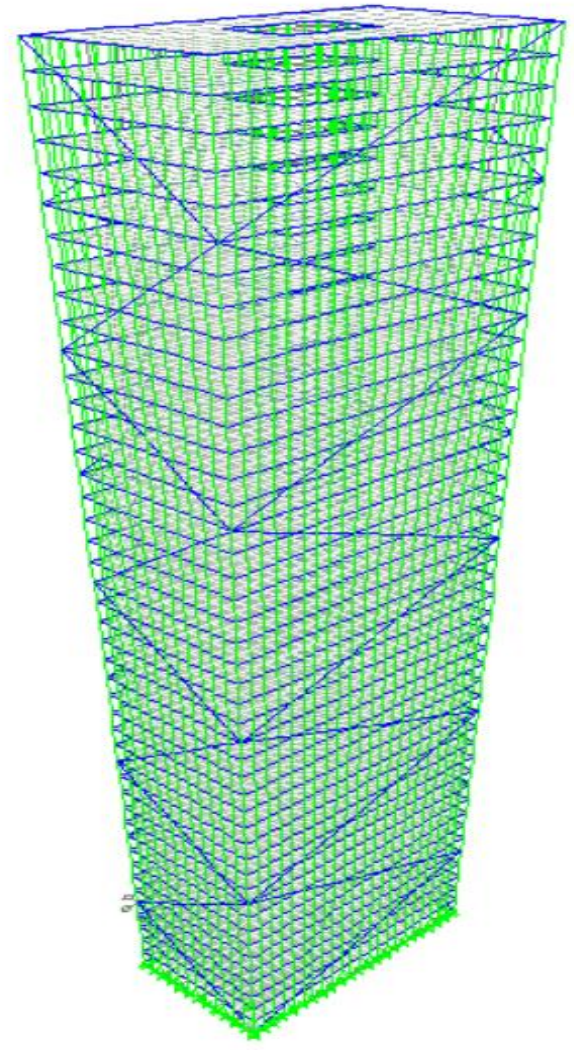

Fig - 6: Steel Tubular Structure with Mega Bracing System Model M3

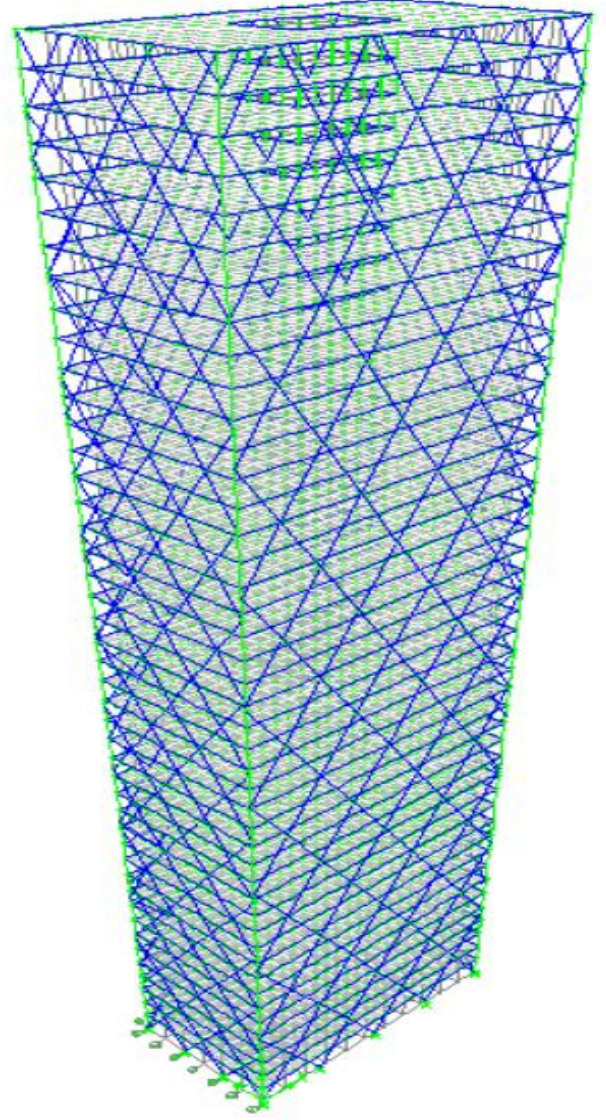

Fig - 7: Steel Tubular Structure with Diagrid Bracing System Model M4

\section{RESULTS AND DISCUSSIONS}

Here the results of frame structure and tubular structure with different bracing system are compared after their analysis in ETABS equivalent static and response spectrum methods. The results considered for the following parameters.

1. Point displacement

2. Storey drift

3. Modal analysis

4. Time history results

The models and their abbreviations are given below:

a) FRAME STRUCTURE - M1

b) TUBE STRUCTURE - M2

c) TUBE STRUCTURE WITH MEGA BRACINGS M3

d) TUBE STRUCTURE WITH DIAGRID BRACINGS - M4

\subsection{Lateral Displacements}

The results for the maximum displacements for frame structure and tubular structural with different bracing systems (45 storey) obtained from seismic analysis along $\mathrm{x}$ and $\mathrm{y}$ direction are obtained and are compared between them in table further graphs for the same results are provided. Displacement values in $\mathrm{mm}$. 
Table - 3: Displacement for 45 storey seismic analysis in $\mathrm{X}$ - direction

\begin{tabular}{|c|c|c|c|c|}
\hline \multicolumn{5}{|c|}{ Displacement for EQX mm } \\
\hline Storey & M1 & M2 & M3 & M4 \\
\hline STOREY45 & 200 & 142 & 123 & 221 \\
\hline STOREY44 & 198 & 140 & 121 & 216 \\
\hline STOREY43 & 196 & 138 & 119 & 210 \\
\hline STOREY42 & 193 & 136 & 117 & 205 \\
\hline STOREY41 & 190 & 133 & 115 & 200 \\
\hline STOREY40 & 187 & 130 & 112 & 194 \\
\hline STOREY39 & 183 & 128 & 110 & 187 \\
\hline STOREY38 & 180 & 125 & 107 & 181 \\
\hline STOREY37 & 176 & 122 & 105 & 175 \\
\hline STOREY36 & 172 & 119 & 102 & 169 \\
\hline STOREY35 & 168 & 116 & 99 & 162 \\
\hline STOREY34 & 164 & 113 & 96 & 155 \\
\hline STOREY33 & 159 & 109 & 93 & 149 \\
\hline STOREY32 & 155 & 106 & 90 & 143 \\
\hline STOREY31 & 150 & 102 & 87 & 137 \\
\hline STOREY30 & 145 & 99 & 84 & 130 \\
\hline STOREY29 & 140 & 95 & 81 & 124 \\
\hline STOREY28 & 136 & 92 & 78 & 118 \\
\hline STOREY27 & 131 & 88 & 75 & 112 \\
\hline STOREY26 & 125 & 85 & 72 & 106 \\
\hline STOREY25 & 120 & 81 & 69 & 100 \\
\hline STOREY24 & 115 & 77 & 65 & 94 \\
\hline STOREY23 & 110 & 73 & 62 & 88 \\
\hline STOREY22 & 105 & 70 & 59 & 83 \\
\hline STOREY21 & 99 & 66 & 56 & 77 \\
\hline STOREY20 & 94 & 62 & 52 & 72 \\
\hline STOREY19 & 89 & 59 & 49 & 66 \\
\hline STOREY18 & 84 & 55 & 46 & 62 \\
\hline STOREY17 & 78 & 51 & 43 & 58 \\
\hline STOREY16 & 73 & 48 & 40 & 53 \\
\hline STOREY15 & 68 & 44 & 37 & 49 \\
\hline STOREY14 & 63 & 41 & 34 & 45 \\
\hline STOREY13 & 58 & 37 & 31 & 41 \\
\hline STOREY12 & 52 & 34 & 28 & 38 \\
\hline STOREY11 & 47 & 30 & 25 & 34 \\
\hline STOREY10 & 42 & 27 & 22 & 31 \\
\hline STOREY9 & 38 & 24 & 20 & 27 \\
\hline STOREY8 & 33 & 21 & 17 & 24 \\
\hline STOREY7 & 28 & 18 & 15 & 21 \\
\hline STOREY6 & 23 & 15 & 12 & 18 \\
\hline STOREY5 & 19 & 12 & 10 & 15 \\
\hline STOREY4 & 14 & 9 & 8 & 11 \\
\hline STOREY3 & 10 & 7 & 5 & 8 \\
\hline STOREY2 & 6 & 4 & 3 & 5 \\
\hline STOREY1 & 2 & 2 & 2 & 2 \\
\hline
\end{tabular}

Storey v/s Displacement (mm) - EQX

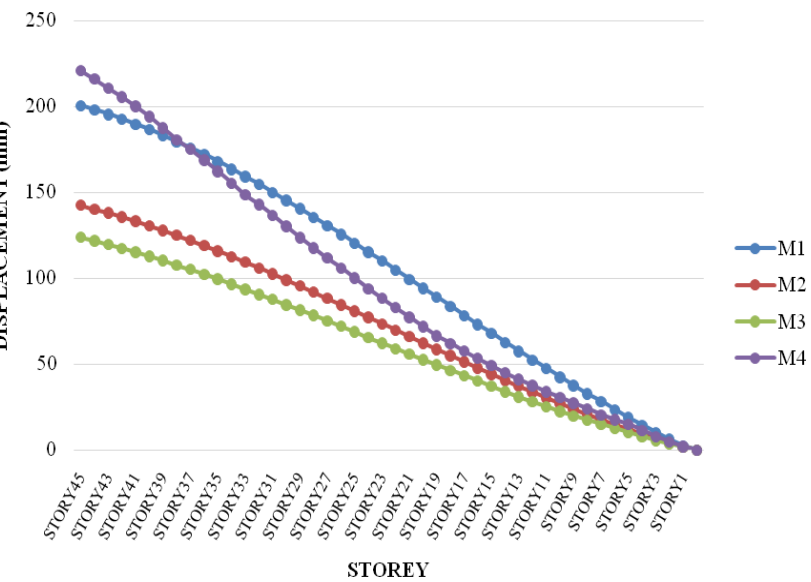

Fig - 8: Storey displacement in $\mathrm{x}$ direction for 45 storey seismic analysis

Observations and Discussions: From the above graph, it is observed that as the height of building increases, displacement stories also increases. The model M1 showing displacement of $200 \mathrm{~mm}$ at the $45^{\text {th }}$ storey and it has been considered as Datum line. The model M2, M3, and M4 correspondingly showing the displacement of $142 \mathrm{~mm}$, $123 \mathrm{~mm}$, and $221 \mathrm{~mm}$ respectively. From the above statistics the model M3 shows reduction in displacement up to $38.5 \%$ of $\mathrm{M} 1,13.38 \%$ of $\mathrm{M} 2$, and $79.67 \%$ of M4. As per the economical view and codal provision the model M4 shows best suitable for practical application.

Table - 4: Displacement for 45 storey seismic analysis in $\mathrm{Y}$-direction

\begin{tabular}{|c|c|c|c|c|}
\hline \multicolumn{5}{|c|}{ Displacement for EQY mm } \\
\hline Storey & M1 & M2 & M3 & M4 \\
\hline STOREY45 & 363 & 322 & 270 & 524 \\
\hline STOREY44 & 357 & 316 & 265 & 510 \\
\hline STOREY43 & 351 & 310 & 260 & 495 \\
\hline STOREY42 & 344 & 304 & 254 & 480 \\
\hline STOREY41 & 337 & 298 & 248 & 465 \\
\hline STOREY40 & 330 & 291 & 243 & 450 \\
\hline STOREY39 & 323 & 284 & 237 & 435 \\
\hline STOREY38 & 315 & 277 & 231 & 420 \\
\hline STOREY37 & 307 & 270 & 224 & 405 \\
\hline STOREY36 & 299 & 263 & 218 & 389 \\
\hline STOREY35 & 291 & 255 & 211 & 374 \\
\hline STOREY34 & 282 & 248 & 204 & 359 \\
\hline STOREY33 & 274 & 240 & 197 & 344 \\
\hline STOREY32 & 265 & 232 & 191 & 329 \\
\hline STOREY31 & 256 & 224 & 184 & 314 \\
\hline STOREY30 & 247 & 216 & 177 & 298 \\
\hline STOREY29 & 237 & 207 & 170 & 283 \\
\hline STOREY28 & 228 & 199 & 163 & 269 \\
\hline STOREY27 & 219 & 191 & 156 & 254 \\
\hline STOREY26 & 209 & 182 & 149 & 240 \\
\hline STOREY25 & 200 & 174 & 141 & 226 \\
\hline STOREY24 & 191 & 165 & 134 & 211 \\
\hline STOREY23 & 181 & 157 & 127 & 197 \\
\hline STOREY22 & 172 & 148 & 120 & 184 \\
\hline
\end{tabular}




\begin{tabular}{|c|c|c|c|c|}
\hline STOREY21 & 162 & 140 & 113 & 171 \\
\hline STOREY20 & 153 & 131 & 106 & 158 \\
\hline STOREY19 & 143 & 123 & 99 & 145 \\
\hline STOREY18 & 134 & 115 & 92 & 133 \\
\hline STOREY17 & 125 & 107 & 86 & 121 \\
\hline STOREY16 & 116 & 98 & 79 & 109 \\
\hline STOREY15 & 107 & 91 & 72 & 99 \\
\hline STOREY14 & 98 & 83 & 65 & 88 \\
\hline STOREY13 & 90 & 75 & 59 & 78 \\
\hline STOREY12 & 81 & 68 & 53 & 68 \\
\hline STOREY11 & 73 & 60 & 47 & 59 \\
\hline STOREY10 & 65 & 53 & 42 & 51 \\
\hline STOREY9 & 57 & 46 & 36 & 42 \\
\hline STOREY8 & 49 & 40 & 31 & 35 \\
\hline STOREY7 & 42 & 34 & 26 & 28 \\
\hline STOREY6 & 35 & 28 & 22 & 21 \\
\hline STOREY5 & 28 & 22 & 17 & 15 \\
\hline STOREY4 & 21 & 16 & 12 & 11 \\
\hline STOREY3 & 15 & 11 & 8 & 7 \\
\hline STOREY2 & 9 & 7 & 5 & 3 \\
\hline STOREY1 & 3 & 3 & 2 & 1 \\
\hline BASE & 0 & 0 & 0 & 0 \\
\hline
\end{tabular}

Table - 5: Storey Drift for 45 storey static analysis in $\quad \mathrm{X}-$ direction

\begin{tabular}{|c|c|c|c|c|}
\hline \multicolumn{5}{|c|}{ Storey Drift for EQX mm } \\
\hline Storey & M1 & M2 & M3 & M4 \\
\hline STOREY45 & 0.00059 & 0.00054 & 0.00051 & 0.00122 \\
\hline STOREY44 & 0.00064 & 0.00057 & 0.00053 & 0.00135 \\
\hline STOREY43 & 0.00069 & 0.0006 & 0.00055 & 0.00128 \\
\hline STOREY42 & 0.00075 & 0.00063 & 0.00058 & 0.00138 \\
\hline STOREY41 & 0.0008 & 0.00066 & 0.00062 & 0.0015 \\
\hline STOREY40 & 0.00085 & 0.00069 & 0.00064 & 0.00162 \\
\hline STOREY39 & 0.0009 & 0.00071 & 0.00065 & 0.00171 \\
\hline STOREY38 & 0.00094 & 0.00074 & 0.00066 & 0.00147 \\
\hline STOREY37 & 0.00098 & 0.00076 & 0.00069 & 0.00154 \\
\hline STOREY36 & 0.00102 & 0.00078 & 0.00072 & 0.00163 \\
\hline STOREY35 & 0.00106 & 0.00081 & 0.00074 & 0.00173 \\
\hline STOREY34 & 0.0011 & 0.00082 & 0.00074 & 0.00169 \\
\hline STOREY33 & 0.00113 & 0.00084 & 0.00074 & 0.00148 \\
\hline STOREY32 & 0.00116 & 0.00086 & 0.00076 & 0.00155 \\
\hline STOREY31 & 0.00118 & 0.00087 & 0.00079 & 0.0016 \\
\hline STOREY30 & 0.00121 & 0.00089 & 0.00081 & 0.00166 \\
\hline STOREY29 & 0.00123 & 0.0009 & 0.0008 & 0.00153 \\
\hline STOREY28 & 0.00125 & 0.00091 & 0.00079 & 0.00144 \\
\hline STOREY27 & 0.00127 & 0.00092 & 0.0008 & 0.00147 \\
\hline STOREY26 & 0.00128 & 0.00092 & 0.00083 & 0.00149 \\
\hline STOREY25 & 0.00129 & 0.00093 & 0.00084 & 0.00154 \\
\hline STOREY24 & 0.0013 & 0.00093 & 0.00082 & 0.00142 \\
\hline STOREY23 & 0.00131 & 0.00093 & 0.0008 & 0.00136 \\
\hline STOREY22 & 0.00132 & 0.00093 & 0.0008 & 0.00139 \\
\hline STOREY21 & 0.00132 & 0.00093 & 0.00083 & 0.00137 \\
\hline STOREY20 & 0.00132 & 0.00093 & 0.00084 & 0.00136 \\
\hline STOREY19 & 0.00132 & 0.00092 & 0.0008 & 0.00114 \\
\hline STOREY18 & 0.00132 & 0.00091 & 0.00078 & 0.00111 \\
\hline STOREY17 & 0.00131 & 0.00091 & 0.00077 & 0.00108 \\
\hline STOREY16 & 0.00131 & 0.0009 & 0.00079 & 0.00105 \\
\hline STOREY15 & 0.0013 & 0.00088 & 0.0008 & 0.00106 \\
\hline STOREY14 & 0.00129 & 0.00087 & 0.00076 & 0.00096 \\
\hline STOREY13 & 0.00127 & 0.00086 & 0.00072 & 0.00091 \\
\hline STOREY12 & 0.00126 & 0.00084 & 0.0007 & 0.00088 \\
\hline STOREY11 & 0.00124 & 0.00082 & 0.00072 & 0.00084 \\
\hline STOREY10 & 0.00122 & 0.0008 & 0.00072 & 0.00088 \\
\hline STOREY9 & 0.0012 & 0.00078 & 0.00067 & 0.00085 \\
\hline STOREY8 & 0.00118 & 0.00076 & 0.00063 & 0.00083 \\
\hline STOREY7 & 0.00116 & 0.00073 & 0.0006 & 0.00076 \\
\hline STOREY6 & 0.00113 & 0.00071 & 0.0006 & 0.0007 \\
\hline STOREY5 & 0.0011 & 0.00068 & 0.0006 & 0.00093 \\
\hline STOREY4 & 0.00107 & 0.00065 & 0.00055 & 0.00086 \\
\hline STOREY3 & 0.00103 & 0.00061 & 0.00051 & 0.00079 \\
\hline STOREY2 & 0.00094 & 0.00058 & 0.00047 & 0.00069 \\
\hline STOREY1 & 0.00059 & 0.00046 & 0.00039 & 0.00051 \\
\hline BASE & 0 & 0 & 0 & 0 \\
\hline
\end{tabular}

Observations and Discussions: From the above graph, it is observed that as the height of building increases, displacement stories also increases. The model M1 showing displacement of $363 \mathrm{~mm}$ at the $45^{\text {th }}$ storey and it has been considered as Datum line. The model M2, M3, and M4 correspondingly showing the displacement of $322 \mathrm{~mm}$, $270 \mathrm{~mm}$, and $524 \mathrm{~mm}$ respectively. From the above statistics the model M3 shows reduction in displacement up to $25.61 \%$ of M1, $16.14 \%$ of M2, and $48.47 \%$ of M4. As per the economical view and codal provision the model

\subsection{Storey Drift}

The results for the Storey Drift for frame structure and tubular structural with different bracing systems (45 storey) obtained from seismic analysis along $\mathrm{x}$ and $\mathrm{y}$ direction are obtained and are compared between them in table further graphs for the same results are provided. Storey Drift values are in $\mathrm{mm}$. 


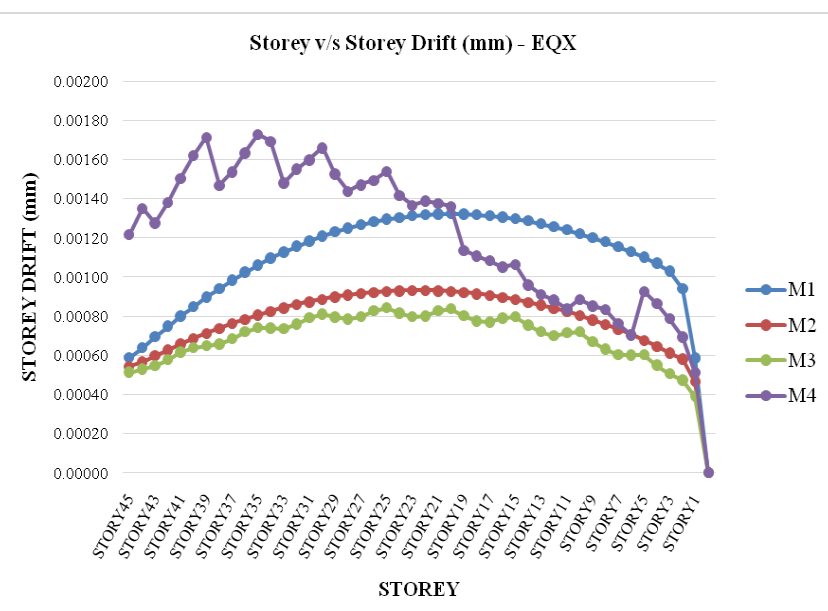

Fig - 10: Storey drift in $\mathrm{x}$ - direction for 45 storey static analysis

Observations and Discussions: From the above graph, it is observed that as the height of building increases, drift stories increases up to $18^{\text {th }}$ and after that it is decreasing. The model M1 showing drift of $0.00132 \mathrm{~mm}$ at the $18^{\text {th }}$ storey and it has been considered as Datum line. The model M2, M3, and M4 correspondingly showing the displacement of $0.00091 \mathrm{~mm}, 0.00078 \mathrm{~mm}$, and $0.00111 \mathrm{~mm}$ respectively. From the above statistics the model M3 shows reduction in displacement up to $31.06 \%$ of $\mathrm{M} 1,14.28 \%$ of $\mathrm{M} 2$, and $29.72 \%$ of M4. Due to the absence of vertical column in M4 model, the inter storey relative displacement is occurring in increasing and decreasing manner.

Table - 6: Storey Drift for 45 storey static analysis in $\quad \mathrm{Y}$ - direction

\begin{tabular}{|c|c|c|c|c|}
\hline \multicolumn{5}{|c|}{ Storey Drift for EQY mm } \\
\hline Storey & M1 & M2 & M3 & M4 \\
\hline STOREY45 & 0.00150 & 0.00149 & 0.00137 & 0.00369 \\
\hline STOREY44 & 0.00157 & 0.00150 & 0.00137 & 0.00371 \\
\hline STOREY43 & 0.00165 & 0.00154 & 0.00140 & 0.00373 \\
\hline STOREY42 & 0.00172 & 0.00160 & 0.00146 & 0.00376 \\
\hline STOREY41 & 0.00179 & 0.00165 & 0.00153 & 0.00377 \\
\hline STOREY40 & 0.00185 & 0.00170 & 0.00156 & 0.00376 \\
\hline STOREY39 & 0.00192 & 0.00175 & 0.00157 & 0.00380 \\
\hline STOREY38 & 0.00197 & 0.00179 & 0.00157 & 0.00382 \\
\hline STOREY37 & 0.00203 & 0.00184 & 0.00163 & 0.00380 \\
\hline STOREY36 & 0.00208 & 0.00188 & 0.00171 & 0.00380 \\
\hline STOREY35 & 0.00213 & 0.00192 & 0.00174 & 0.00384 \\
\hline STOREY34 & 0.00217 & 0.00196 & 0.00171 & 0.00381 \\
\hline STOREY33 & 0.00221 & 0.00199 & 0.00170 & 0.00379 \\
\hline STOREY32 & 0.00224 & 0.00202 & 0.00175 & 0.00379 \\
\hline STOREY31 & 0.00227 & 0.00204 & 0.00183 & 0.00381 \\
\hline STOREY30 & 0.00230 & 0.00207 & 0.00185 & 0.00372 \\
\hline STOREY29 & 0.00232 & 0.00208 & 0.00180 & 0.00367 \\
\hline STOREY28 & 0.00234 & 0.00210 & 0.00177 & 0.00371 \\
\hline STOREY27 & 0.00235 & 0.00211 & 0.00180 & 0.00365 \\
\hline STOREY26 & 0.00236 & 0.00212 & 0.00187 & 0.00351 \\
\hline STOREY25 & 0.00237 & 0.00212 & 0.00189 & 0.00353 \\
\hline STOREY24 & 0.00237 & 0.00212 & 0.00181 & 0.00354 \\
\hline & & & & \\
\hline
\end{tabular}

\begin{tabular}{|c|c|c|c|c|}
\hline STOREY23 & 0.00237 & 0.00212 & 0.00176 & 0.00339 \\
\hline STOREY22 & 0.00236 & 0.00211 & 0.00177 & 0.00327 \\
\hline STOREY21 & 0.00235 & 0.00210 & 0.00183 & 0.00333 \\
\hline STOREY20 & 0.00233 & 0.00209 & 0.00185 & 0.00321 \\
\hline STOREY19 & 0.00232 & 0.00207 & 0.00174 & 0.00311 \\
\hline STOREY18 & 0.00229 & 0.00205 & 0.00167 & 0.00301 \\
\hline STOREY17 & 0.00227 & 0.00202 & 0.00166 & 0.00300 \\
\hline STOREY16 & 0.00224 & 0.00199 & 0.00171 & 0.00274 \\
\hline STOREY15 & 0.00220 & 0.00195 & 0.00172 & 0.00257 \\
\hline STOREY14 & 0.00216 & 0.00191 & 0.00159 & 0.00271 \\
\hline STOREY13 & 0.00212 & 0.00187 & 0.00149 & 0.00248 \\
\hline STOREY12 & 0.00208 & 0.00182 & 0.00146 & 0.00222 \\
\hline STOREY11 & 0.00203 & 0.00177 & 0.00149 & 0.00221 \\
\hline STOREY10 & 0.00197 & 0.00171 & 0.00150 & 0.00218 \\
\hline STOREY9 & 0.00191 & 0.00165 & 0.00134 & 0.00193 \\
\hline STOREY8 & 0.00185 & 0.00158 & 0.00123 & 0.00166 \\
\hline STOREY7 & 0.00179 & 0.00151 & 0.00117 & 0.00180 \\
\hline STOREY6 & 0.00172 & 0.00143 & 0.00116 & 0.00149 \\
\hline STOREY5 & 0.00165 & 0.00134 & 0.00117 & 0.00120 \\
\hline STOREY4 & 0.00157 & 0.00125 & 0.00099 & 0.00111 \\
\hline STOREY3 & 0.00148 & 0.00114 & 0.00086 & 0.00106 \\
\hline STOREY2 & 0.00135 & 0.00104 & 0.00075 & 0.00057 \\
\hline STOREY1 & 0.00087 & 0.00072 & 0.00053 & 0.00020 \\
\hline BASE & 0 & 0 & 0 & 0 \\
\hline
\end{tabular}

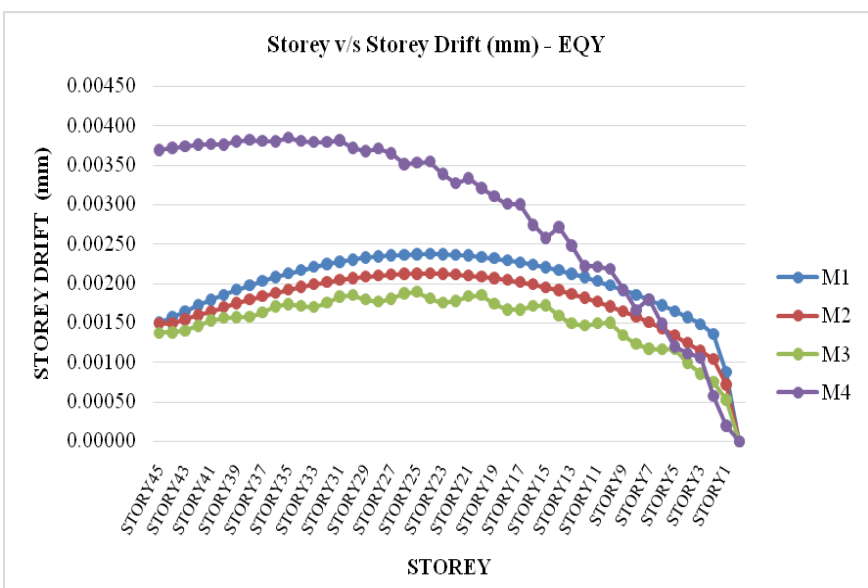

Fig - 11: Storey drift in Y - direction for 45 storey static analysis

Observations and Discussions: From the above graph, it is observed that as the height of building increases, drift stories increases up to $23^{\text {th }}$ storey and after that it is decreasing. The model M1 showing drift of $0.00237 \mathrm{~mm}$ at the $23^{\text {th }}$ storey and it has been considered as Datum line. The model M2, M3, and M4 correspondingly showing the drift of $0.00212 \mathrm{~mm}, 0.00176 \mathrm{~mm}$, and $0.00339 \mathrm{~mm}$ respectively. From the above statistics the model M3 shows reduction in displacement up to $25.73 \%$ of M1, $16.98 \%$ of $\mathrm{M} 2$, and $48.08 \%$ of M4. Due to the absence of vertical column in M4 model, the inter storey relative displacement is occurring in increasing and decreasing manner.

\section{3modal Analysis}

The results for Modal Analysis are obtained in the form of Modes against Period and Modes against Frequency. The results for Modes against Period are given in Table - 7 and plotted in the form of graph given in Fig -12. Similarly the 
results for Modes against Frequency are given in the Table 8 and plotted in a graph given in Fig - 13 .

Table - 7: Modal Analysis with respect to Period

\begin{tabular}{|c|c|c|c|c|}
\hline & \multicolumn{4}{|c|}{ Period (Seconds) } \\
\hline Mode & M1 & M2 & M3 & M4 \\
\hline 1 & 7.37 & 6.88 & 6.24 & 8.26 \\
\hline 2 & 5.64 & 4.66 & 4.3 & 5.45 \\
\hline 3 & 5.26 & 3.15 & 2.69 & 2.18 \\
\hline 4 & 2.24 & 2.04 & 1.8 & 2.18 \\
\hline 5 & 1.8 & 1.44 & 1.32 & 2.01 \\
\hline 6 & 1.74 & 1.06 & 0.92 & 1.86 \\
\hline 7 & 1.18 & 1.05 & 0.89 & 1.84 \\
\hline 8 & 1.02 & 0.77 & 0.7 & 1.71 \\
\hline 9 & 1 & 0.72 & 0.62 & 1.42 \\
\hline 10 & 0.82 & 0.62 & 0.53 & 1.42 \\
\hline 11 & 0.72 & 0.54 & 0.48 & 1.3 \\
\hline 12 & 0.7 & 0.54 & 0.47 & 1.08 \\
\hline
\end{tabular}

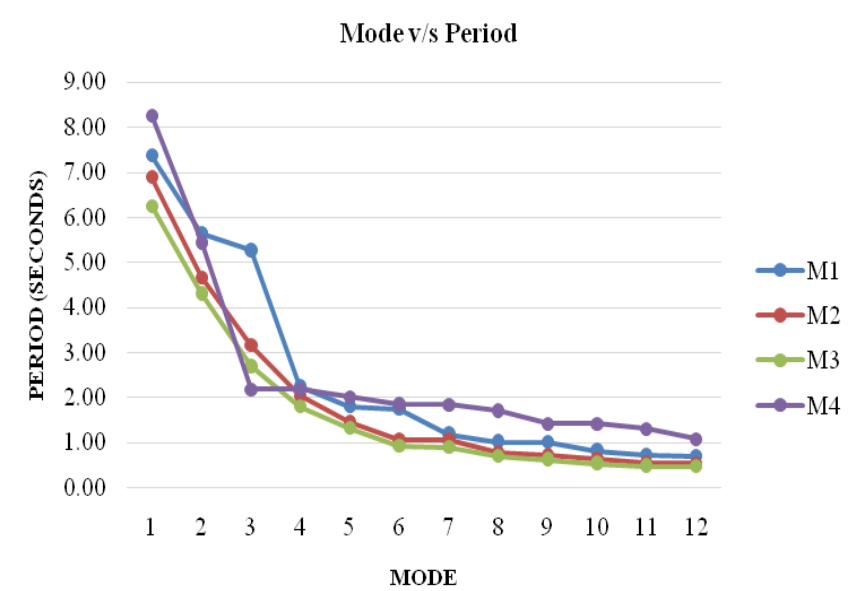

Fig - 12: Graphical Representation of Modal Analysis in terms of Period

Table - 8: Modal Analysis with respect to Frequency

\begin{tabular}{|c|c|c|c|c|}
\hline \multicolumn{5}{|c|}{ Frequency $(\mathbf{H z})$} \\
\hline Mode & M1 & M2 & M3 & M4 \\
\hline 1 & 0.14 & 0.15 & 0.16 & 0.12 \\
\hline 2 & 0.18 & 0.21 & 0.23 & 0.18 \\
\hline 3 & 0.19 & 0.32 & 0.37 & 0.46 \\
\hline 4 & 0.45 & 0.49 & 0.56 & 0.46 \\
\hline 5 & 0.55 & 0.69 & 0.76 & 0.5 \\
\hline 6 & 0.58 & 0.95 & 1.09 & 0.54 \\
\hline 7 & 0.84 & 0.95 & 1.12 & 0.54 \\
\hline 8 & 0.98 & 1.29 & 1.43 & 0.58 \\
\hline 9 & 1 & 1.39 & 1.61 & 0.7 \\
\hline 10 & 1.22 & 1.6 & 1.89 & 0.7 \\
\hline 11 & 1.39 & 1.85 & 2.07 & 0.77 \\
\hline 12 & 1.43 & 1.87 & 2.13 & 0.93 \\
\hline
\end{tabular}

Modev/s Frequency

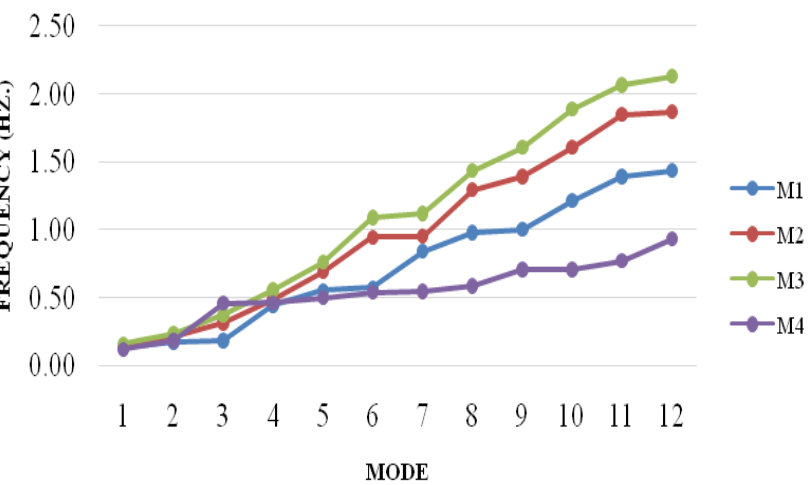

Fig - 13: Graphical Representation of Modal Analysis in terms of Frequency

Observations And Discussions: From Fig -12 and 13, the graph showing mode v/s period and mode v/s frequency for all types of models such as M1, M2, M3, and M4. We can notice that model M4 is with least frequency and higher period. For mode 1, the frequency of Diagrid tube structure has lowest of all compared to other models that is $0.12 \mathrm{~Hz}$ and maximum period of 8.26 seconds.

\subsection{Time History Results}

The results of Time History Analysis are given below for different models M1, M2, M3 and M4 in both $\mathrm{X}$ and $\mathrm{Y}$ directions.

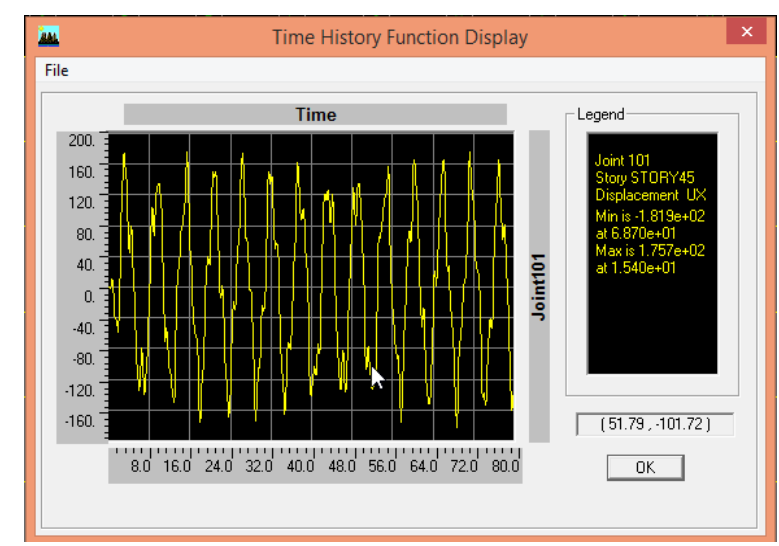

Fig - 14: Peak Displacement in $\mathrm{X}$ - direction in M1

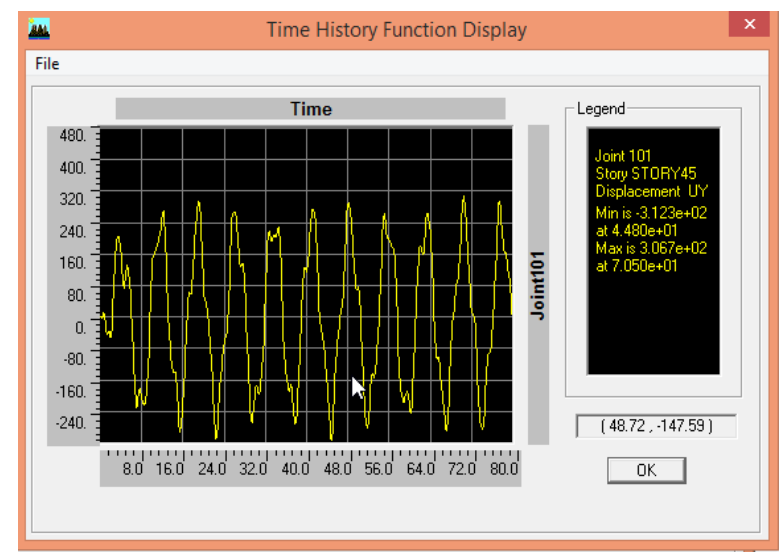

Fig - 15: Peak Displacement in $\mathrm{Y}$ - direction in M1 


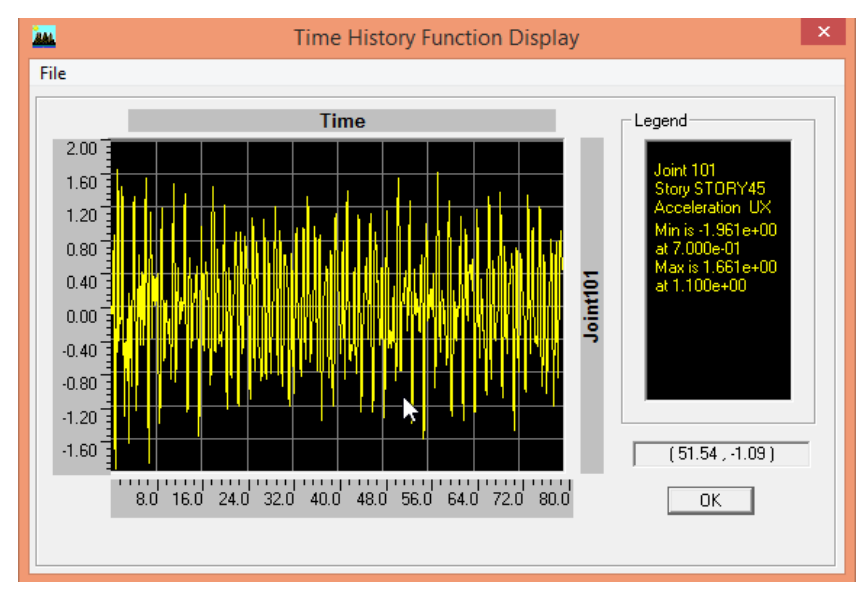

Fig - 16: Peak Acceleration in $\mathrm{X}$ - direction in $\mathrm{M} 1$

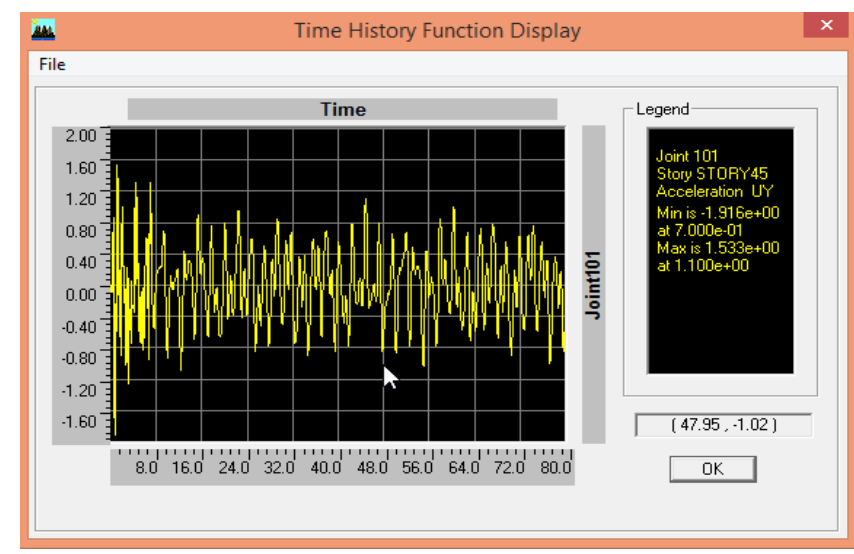

Fig - 17: Peak Acceleration in $\mathrm{Y}$ - direction in M1

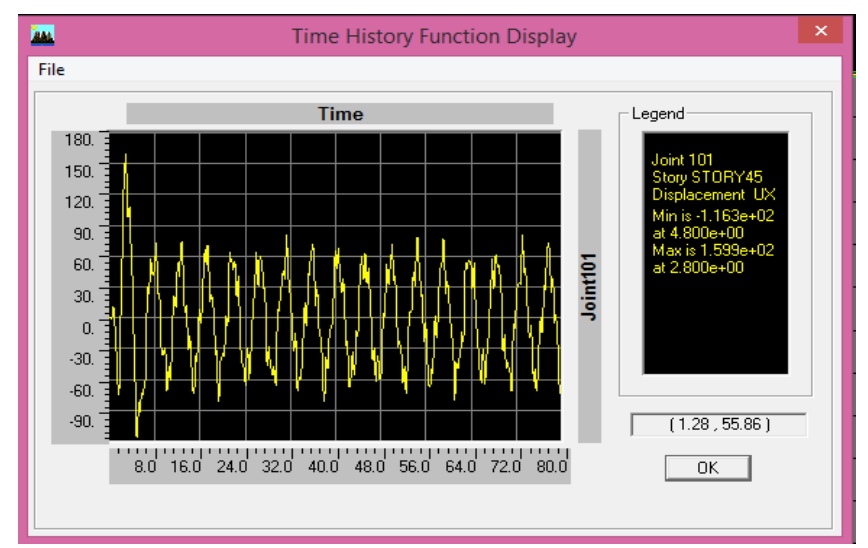

Fig - 18: Peak Displacement in $X$ - direction in $M 2$

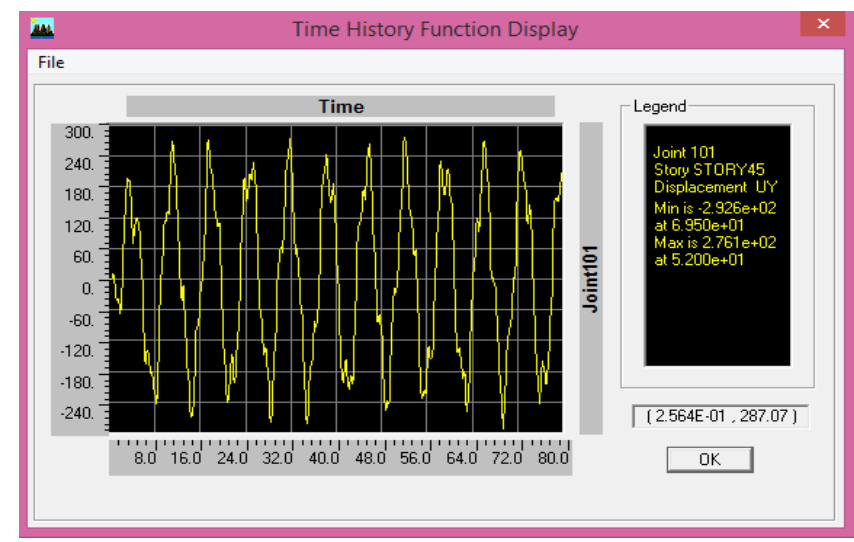

Fig - 19: Peak Displacement in $\mathrm{Y}$ - direction in M2

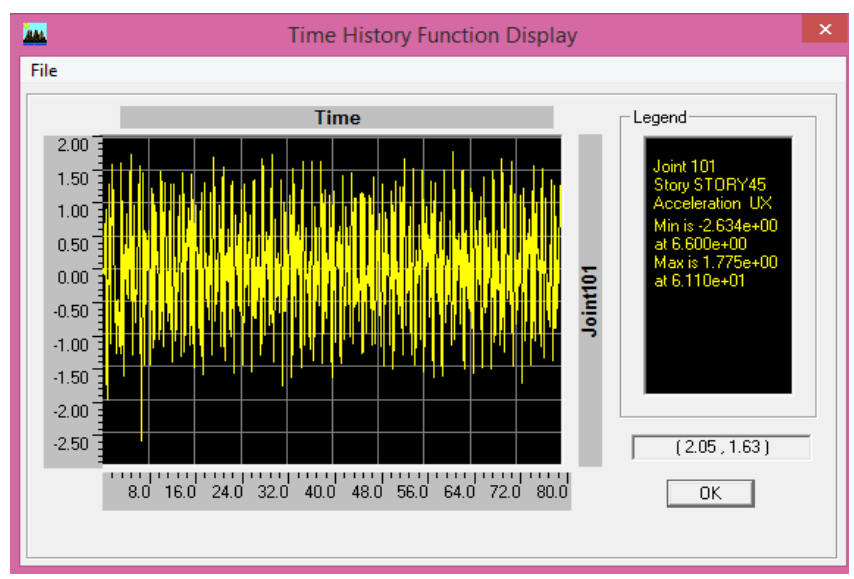

Fig - 20: Peak Acceleration in $\mathrm{X}$ - direction in M2

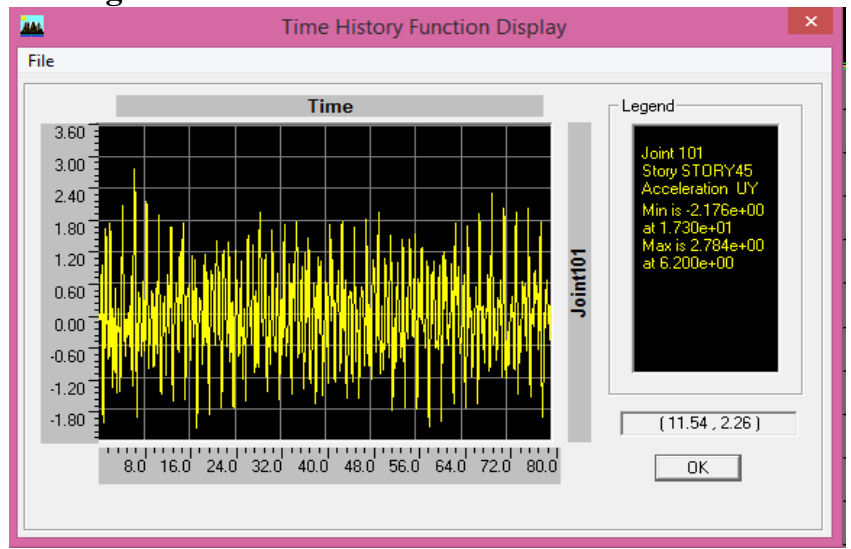

Fig - 21: Peak Acceleration in $\mathrm{Y}$ - direction in M2

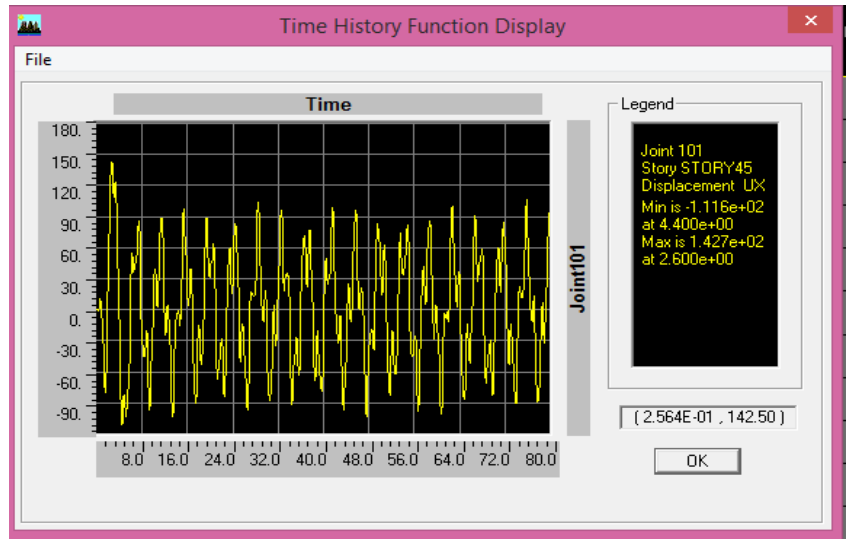

Fig - 22: Peak Displacement in $\mathrm{X}$ - direction in M3

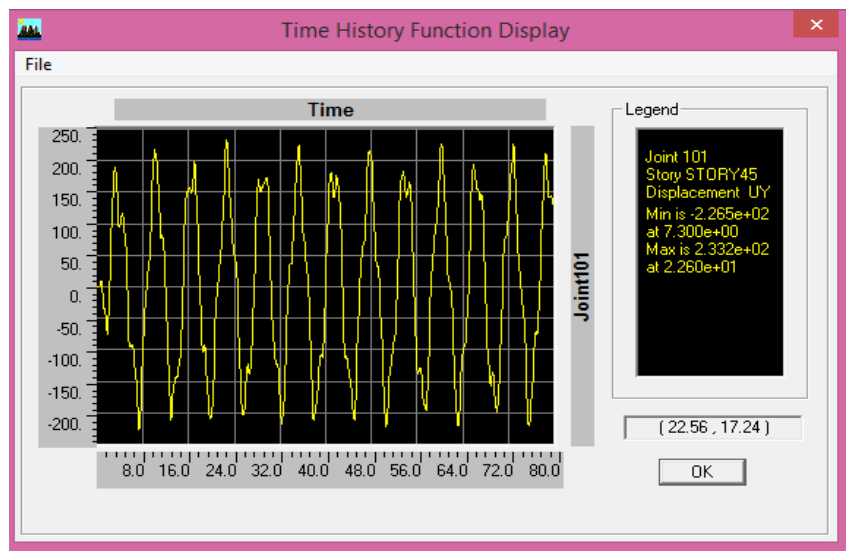

Fig - 23: Peak Displacement in $\mathrm{Y}$ - direction in M3 


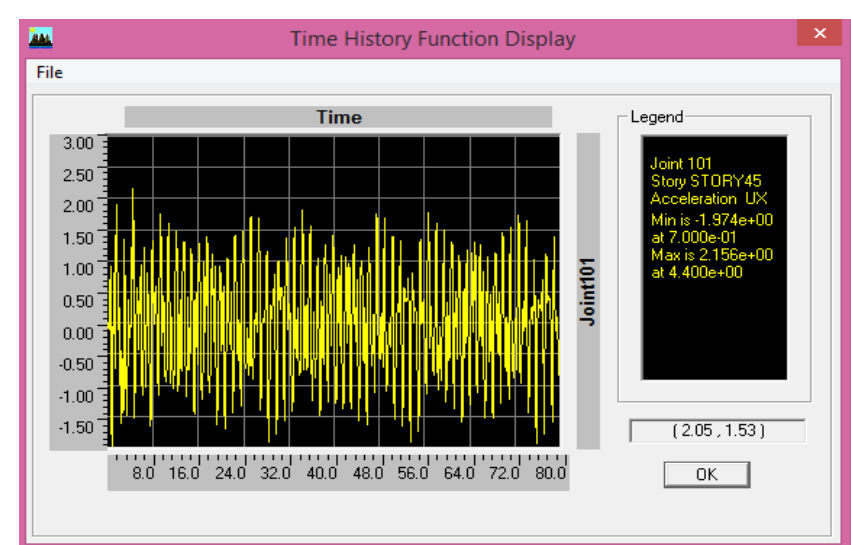

Fig - 24: Peak Acceleration in $\mathrm{X}$ - direction in M3

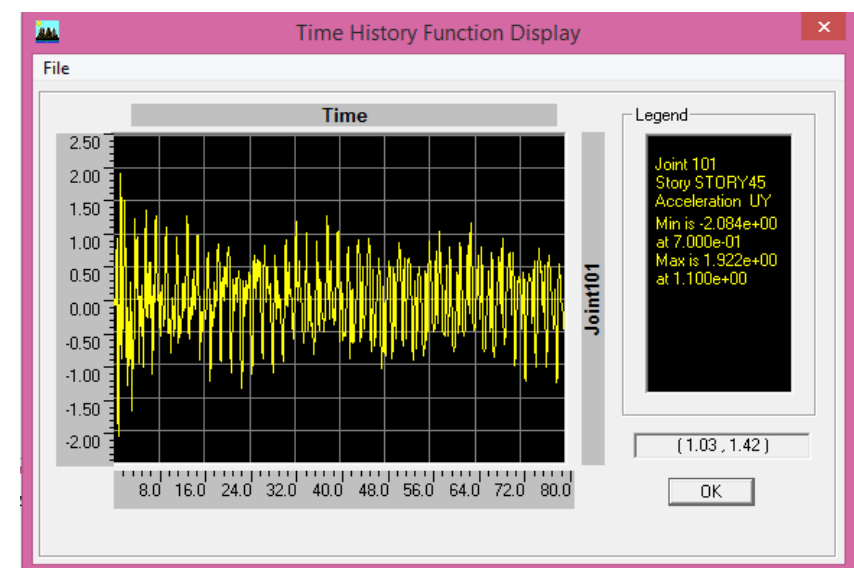

Fig - 25: Peak Acceleration in $\mathrm{Y}$ - direction in M3

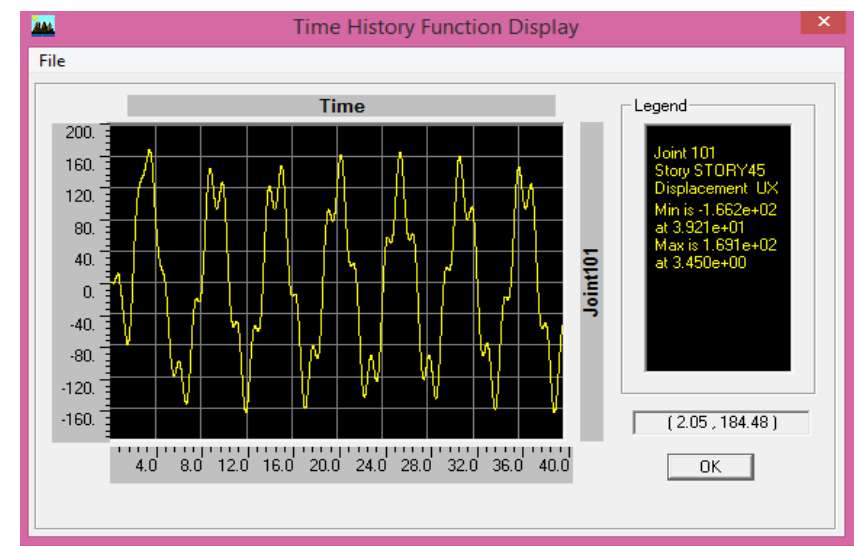

Fig - 26: Peak Displacement in $\mathrm{X}$ - direction in M4

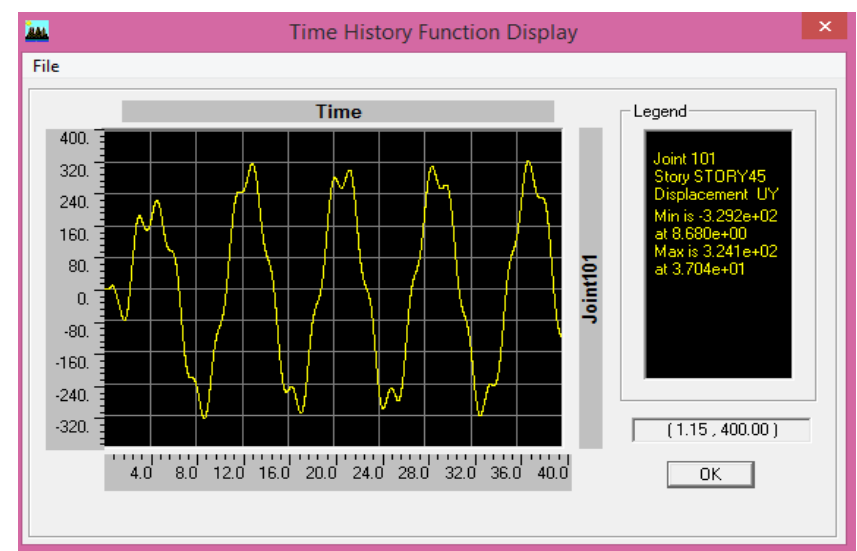

Fig - 27: Peak Displacement in Y - direction in M4

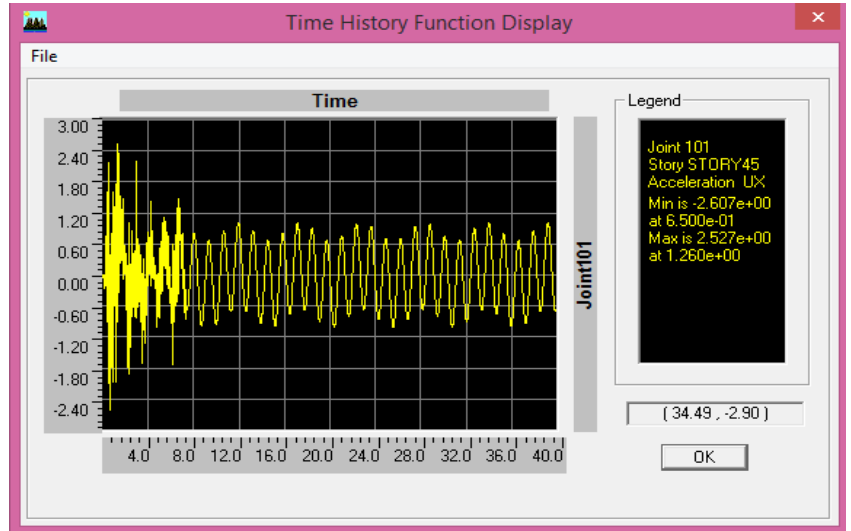

Fig - 28: Peak Acceleration in $\mathrm{X}$ - direction in M4

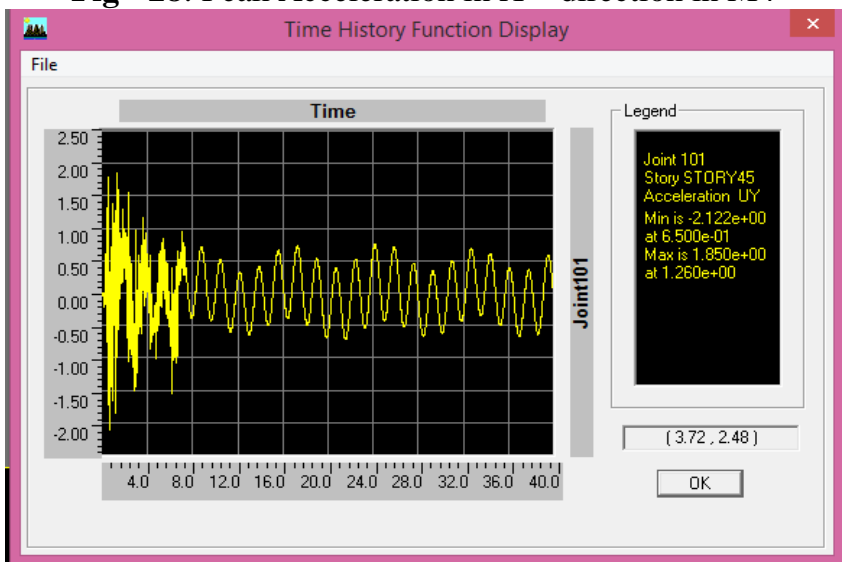

Fig - 29: Peak Acceleration in $\mathrm{Y}$ - direction in M4

Summary of the Time History Analysis Results are tabulated below for Peak Displacement and Peak Acceleration in both $\mathrm{X}$ and $\mathrm{Y}$ directions. Also comparison graphs are plotted.

Table - 9: Time History Results with respect to Peak Displacement

\begin{tabular}{|c|c|c|}
\hline \multicolumn{3}{|c|}{ Peak Displacement (mm) } \\
\hline Model & X - Direction & Y - Direction \\
\hline M1 & 189 & 312 \\
\hline M2 & 160 & 293 \\
\hline M3 & 143 & 233 \\
\hline M4 & 169 & 324 \\
\hline
\end{tabular}

Peak Displacements ( $\mathrm{mm}$ )

$\because \mathrm{X}$ - Direction $\quad \mathrm{Y}$ - Direction

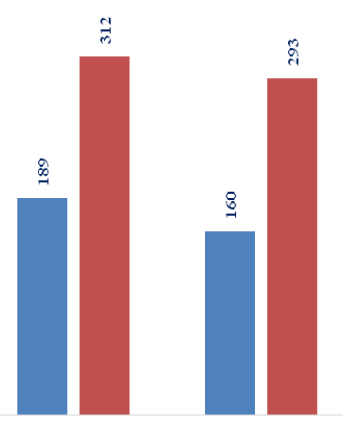

$\mathrm{M}^{2}$

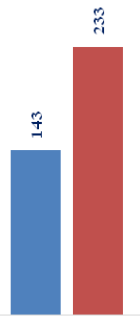

M4 
Observations and Discussions: From the plotted bar chart the peak displacement is observed that model M3 exhibits least displacement in both the direction $\mathrm{x}$ and $\mathrm{y}$, of $24.33 \%$ of M1 x-direction and $25.32 \%$ of M1y-diretion, $10.62 \%$ of $\mathrm{M} 2$ in $\mathrm{x}$-direction and $20.47 \%$ in y-direction, $15.38 \%$ of $\mathrm{M} 4$ in $\mathrm{x}$-direction and $28.08 \%$ of $\mathrm{M} 4$ in $\mathrm{y}-$ direction.

Table - 10: Time History Results with respect to Peak Acceleration

\begin{tabular}{|c|c|c|}
\hline \multicolumn{3}{|c|}{ Peak Acceleration $\left(\mathbf{N} / \mathbf{m}^{\mathbf{2}}\right)$} \\
\hline Model & X - Direction & Y - Direction \\
\hline M1 & 1.96 & 1.91 \\
\hline M2 & 2.63 & 2.78 \\
\hline M3 & 2.15 & 2.08 \\
\hline M4 & 2.6 & 2.1 \\
\hline
\end{tabular}

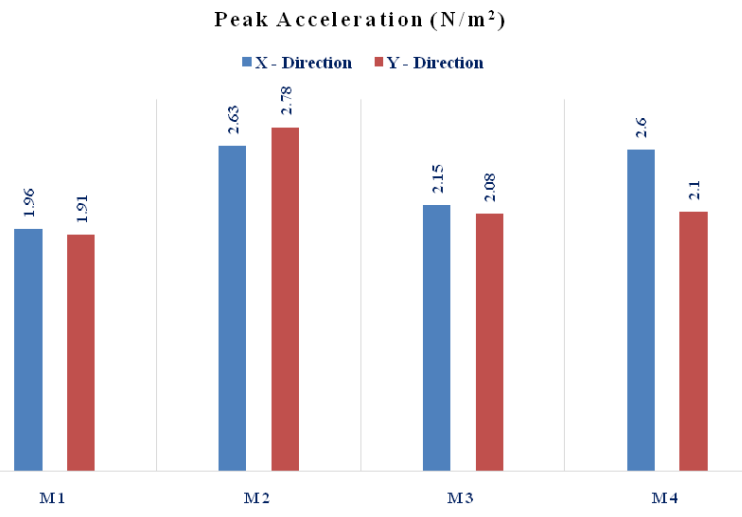

Fig - 31: Showing Peak Acceleration Bar Chart

Observations and Discussions: From the plotted bar chart it is observed that the model M1 showing least peak acceleration in both $1.96 \mathrm{~N} / \mathrm{m}^{2}$ in $\mathrm{x}$ direction and $1.91 \mathrm{~N} / \mathrm{m}^{2}$ in $\mathrm{y}$ direction respectively. And it is taken as datum line. The model M2 it is showing maximum peak acceleration $34.18 \%$ increase of M1 model in x direction and $45.54 \%$ of M1 in y direction. M3 and M4 showing increase in peak acceleration $9.69 \%$ and $32.65 \%$ in $\mathrm{x}$ direction, $8.9 \%$ and $9.94 \%$ in y direction respectively as compared with model M1.

\section{CONCLUSIONS}

$>$ Steel tubular structure system is stiffer than frame structure in terms of displacement, Showing $29 \%$ and $11.29 \%$ decrease in displacement in $\mathrm{x}$ and $\mathrm{y}$ direction of frame structure respectively. And the drift showing $31.06 \%$ and $10.55 \%$ decrease in $\mathrm{x}$ and $\mathrm{y}$ direction respectively compared with frame model.

$>$ The steel tubular structure with Mega Bracing System is most efficient in lateral displacement and drift in both the directions $\mathrm{x}$ and $\mathrm{y}$ respectively, It shows reduction in displacement up to $38.5 \%$ of frame structure, $13.38 \%$ of tubular structure, and $79.67 \%$ of tubular structure with Diagrid Bracing System.

$>$ From the modal analysis result it is observed that Diagrid bracing system showing satisfactory performance by the parametric observation on period and frequency. The frequency of Diagrid tube structure has lowest of all compared to other models that is $0.12 \mathrm{~Hz}$ and maximum period of 8.26 seconds.

$>$ The steel tubular structure with Mega bracing system exhibits least displacement in both the direction $\mathrm{x}$ and $\mathrm{y}$, of $24.33 \%$ of frame structure in $x$-direction and $25.32 \%$ of frame structure in y-direction, $10.62 \%$ of tubular structure in $\mathrm{x}$-direction and $20.47 \%$ of tubular structure in y-direction, $15.38 \%$ of tubular structure with Diagrid bracing system in $\mathrm{x}$-direction and $28.08 \%$ in $\mathrm{y}$ direction.

\section{ACKNOWLEDGEMENT}

First and foremost, praise and thanks goes to my God and Parents for the blessing that has bestowed upon me in all my endeavors. I am deeply indebted to Naveena M P, Assistant Professor of Structural Engineering Division, my advisor and guide, for the motivation, guidance, tutelage and patience throughout the project work. I appreciate her broad range of expertise and attention to detail, as well as the constant encouragement he has given me over the years.

\section{REFERENCES}

[1]. David Spires and J. S. Arora (April 1990) "Optimal design of tall RC-framed Tube buildings" American society of civil engineering-Journal of Structural Engineering, Vol. 116, No. 4.

[2]. Harish Varsani, Narendra Pokar, Dipesh Gandhi (January 2015) "Comparative Analysis of Diagrid Structural System and Conventional structural System for High Rise Steel Building" International Journal of Advance Research in Engineering Science \& Technology, volume 2, issue 1.

[3]. K. Moon (2009) "Design and Construction of Steel Diagrid Structures" School of Architecture, YAle University, New Haven, USA. NSSC -2009, pp398-405.

[4]. KYOUNG-SUN MOOON, JEROME J.CONNOR and JOHN E.FERNANDEZ (2007) "Diagrid Structural Systems for Tall Buildings: Characteristics and Methodology for Preliminary Design" Wiley Interscience, pp 205-230.

[5]. T. M. Boake "Diagrid Structures :Innovation and Detailing " School of Architecture, University of Waterloo, Canada.

\section{BIOGRAPHIES}

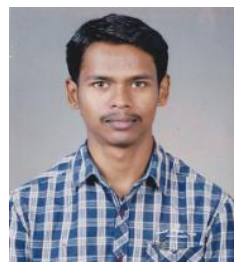

Dhanapalagoud Patil. Student, Structural Engineering, MVJ College of Engineering, Bangalore.

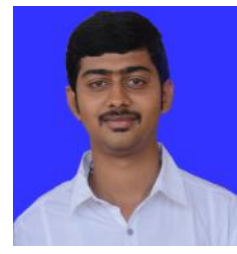

Naveena M P. Assistant Professor, Structural Engineering, MVJ College of Engineering Bangalore. 